Article

\title{
Harmonized Collaborative Validation of Aflatoxins and Sterigmatocystin in White Rice and Sorghum by Liquid Chromatography Coupled to Tandem Mass Spectrometry
}

\author{
Hyun Ee Ok ${ }^{1}$, Fei Tian ${ }^{1}$, Eun Young Hong ${ }^{1}$, Ockjin Paek ${ }^{2}$, Sheen-Hee Kim ${ }^{2}$, Dongsul Kim ${ }^{2}$ \\ and Hyang Sook Chun ${ }^{1, *}$ \\ 1 Advanced Food Safety Research Group, BK21 Plus, School of Food Science and Technology, \\ Chung-Ang University, Anseong 17546, Korea; ohe0904@hanmail.net (H.E.O.); TianFei@cau.ac.kr (F.T.); \\ eyhongs@gmail.com (E.Y.H.) \\ 2 Food Contaminants Division, National Institute of Food \& Drug Safety Evaluation, Osong 28159, Korea; \\ ojpaek92@korea.kr (O.P.); cinee@korea.kr (S.-H.K.); dongsul@korea.kr (D.K.) \\ * Correspondence: hschun@cau.ac.kr; Tel.: +82-10-8946-9273
}

Academic Editor: Aldo Laganà

Received: 5 October 2016; Accepted: 6 December 2016; Published: 13 December 2016

\begin{abstract}
An interlaboratory study was performed in eight laboratories to validate a liquid chromatography-tandem mass spectrometry (LC/MS/MS) method for the simultaneous determination of aflatoxins and sterigmatocystin (STC) in white rice and sorghum (Sorghum bicolor). Fortified samples (at three different levels) of white rice and sorghum were extracted, purified through a solid-phase extraction (SPE) column, and then analyzed by LC/MS/MS. The apparent recoveries (ARs) ranged from $78.8 \%$ to $95.0 \%$ for aflatoxins and from $85.3 \%$ to $96.7 \%$ for STC. The relative standard deviations for repeatability $\left(\mathrm{RSD}_{\mathrm{r}}\right.$ ) and reproducibility (RSDR) of aflatoxins were in the ranges $7.9 \%-33.8 \%$ and $24.4 \%-81.0 \%$, respectively. For STC, the RSD $_{r}$ ranged from $7.1 \%$ to $40.2 \%$ and the RSDR ranged from $28.1 \%$ to $99.2 \%$. The Horwitz ratio values for the aflatoxins and STC ranged from 0.4 to 1.2 in white rice and from 0.3 to 1.0 in sorghum, respectively. These results validated this method for the simultaneous determination of aflatoxins and STC by LC/MS/MS after SPE column cleanup. The percentages of satisfactory $Z$-score values $(|Z| \leq 2)$ were the following: for white rice, $100 \%$ for aflatoxins and STC; for sorghum, 100\%, except in data from two laboratories for STC $(0.3 \mu \mathrm{g} / \mathrm{kg})$. This validated that the LC/MS/MS method was successfully applied for the determination of aflatoxins and STC in 20 white rice and 20 sorghum samples sourced from Korean markets.
\end{abstract}

Keywords: aflatoxins; sterigmatocystin; simultaneous determination; liquid chromatography-tandem mass spectrometry

\section{Introduction}

Concern about human exposure to aflatoxins has tended inevitably to focus on high-risk commodities such as corn, nuts, and dried fruit, where levels of aflatoxins can be both variable and relatively high [1,2]. Although it is known that cereals can be contaminated with aflatoxins, the research emphasis, e.g., for wheat, has tended towards the monitoring and control of Fusarium toxins, where toxins such as deoxynivalenol commonly and frequently occur at $\mathrm{mg} / \mathrm{kg}$ levels [3]. Although rice is not immediately thought of as a high-risk commodity in terms of contamination levels of aflatoxins, there is substantial evidence indicating endemic low concentration $(\mathrm{mg} / \mathrm{kg})$ occurrence of aflatoxin $\mathrm{B}_{1}$ contamination in rice $[4,5]$. Because rice is a staple food worldwide, low-level contamination can 
be of concern because it can lead to long-term exposure at above recommended levels. Sorghum is another important cereal crop worldwide. It is used in food items such as cookies, cakes, porridge, unleavened bread, and beverages [6]. Sorghum contains significant amounts of tannins in the testa, low amounts of phenolic acids in the grain [7], and abundant polyphenols, which enhance its resistance to pests and microbial infestation [8]. However, sorghum is vulnerable to fungal contamination. It has been estimated that economic losses in Asia and Africa due to fungal infestation were $>\$ 130$ million annually [9]. Aspergillus, Fusarium, Penicillium, and Alternaria species are commonly detected in contaminated sorghum, and mycotoxigenic strains of these fungal species have been isolated from different sorghum varieties [9].

Aflatoxins is a family of structurally related mycotoxins that includes aflatoxin $B_{1}\left(A_{F} B_{1}\right)$, aflatoxin $B_{2}\left(A F B_{2}\right)$, aflatoxin $G_{1}\left(A F G_{1}\right)$, and aflatoxin $G_{2}\left(A F G_{2}\right)$ [10]. These are the most important mycotoxins detected in food [11] and have been classified in group 1 as human carcinogens by the International Agency for Research on Cancer [12]. Many strains of Aspergillus, such as Aspergillus flavus, Aspergillus parasiticus, Aspergillus bombycis, Aspergillus ochraceoroseus, Aspergillus nomius, and Aspergillus pseudotamari can produce aflatoxins [13]. Maximum levels of aflatoxin contamination have been established by different countries to protect public health. In particular, the European Commission regulated $2 \mu \mathrm{g} / \mathrm{kg}$ for $\mathrm{AFB}_{1}$ and $4 \mu \mathrm{g} / \mathrm{kg}$ for total aflatoxins in cereals and derived products [14], and the Korea Ministry of Food and Drug Safety imposed limits of $\mathrm{AFB}_{1}<10 \mu \mathrm{g} / \mathrm{kg}$ and total aflatoxins $<15 \mu \mathrm{g} / \mathrm{kg}$ [15].

Sterigmatocystin (STC) is a mycotoxin produced by the fungi of many different Aspergillus species. Other species such as Bipolaris, Chaetomium, and Emericella are also able to produce STC. STC-producing fungi have frequently been isolated from different foodstuffs. STC has been detected regularly in grains, corn, bread, cheese, spices, coffee beans, soybeans, pistachio nuts, animal feed, and silage [16]. STC exhibits various toxicological, mutagenic, and carcinogenic effects in animals, and it has been recognized as a 2B carcinogen (possible human carcinogen) by the International Agency for Research on Cancer [17]. Recent reviews described the occurrence of STC in a variety of foodstuffs [18-20]. The European Food Safety Authority (EFSA) Panel on Contaminants in the Food Chain (CONTAM Panel) analyzed a total of 1259 samples of cereal grains, cereal products, and nuts, collected between August 2013 and November 2014 in nine European countries (and originating from 45 countries), for the presence of STC. In cereal grains, STC was detected in $2 \%-6 \%$ of the wheat, rye, maize, and barley samples, mostly at levels $<1.5 \mu \mathrm{g} / \mathrm{kg}$. A higher incidence and higher levels of contamination (14 samples, 1.5-6 $\mu \mathrm{g} / \mathrm{kg} ; 1$ sample, $33 \mu \mathrm{g} / \mathrm{kg}$ ) were observed in rice (in virtually all unprocessed rice and $21 \%$ of processed rice from the EU) and oats (22\%) [21]. Sorghum is also commonly detected with STC contamination. Queslati et al. [22] analyzed 60 sorghum samples from Tunisian markets; 33\% of them were detected with STC contamination at the mean level of $20.5 \mu \mathrm{g} / \mathrm{kg}$. Chala et al. [23] detected similar levels of contamination $(21.2 \mu \mathrm{g} / \mathrm{kg}$ ) in $34 \%$ of the sorghum samples (70 samples) collected from Ethiopian markets; the highest concentration was $323 \mu \mathrm{g} / \mathrm{kg}$.

Analytical methods involving chromatography have been developed for STC and aflatoxins. Thin-layer chromatography [24], high-performance liquid chromatography (HPLC) [25,26], and gas chromatography [27] have been used. More recently, liquid chromatography-mass spectrometry (LC/MS) methods were reported [28].

Liquid chromatography-tandem mass spectrometry (LC/MS/MS) has been shown to be suitable for the analysis of mycotoxins in cereals [29-31]; it enables simultaneous qualification and quantification. According to the EFSA [32], among the analytical methods available for the determination of STC, LC/MS methods demonstrate the limit of detection (LOD). However, the sensitivity of these methods depends on the matrices and methods used.

In the present study, we validated the method for quantifying aflatoxins and STC in white rice and sorghum (Sorghum bicolor) through an interlaboratory study. The method uses a single solid phase extract column for cleanup, and simultaneous determination by LC/MS/MS for the toxins. 


\section{Results}

\subsection{Collaborative Validation of LC/MS/MS Determination of Aflatoxins and STC in White Rice}

The results of the interlaboratory study of aflatoxins and STC in white rice are tabulated in Table 1. The mean apparent recoveries (ARs) at all spike levels $(0.3-10 \mu \mathrm{g} / \mathrm{kg}$ ) were within the acceptable limits $(70 \%-110 \%)$. However, the mean AR of aflatoxins (89\%) was below the ARs of STC (94\%) and the ARs of $\mathrm{AFG}_{1}$ and $\mathrm{AFG}_{2}(82 \%-88 \%)$ were noticeably lower in comparison with $\mathrm{AFB}_{1}$ and $\mathrm{AFB}_{2}(91 \%-93 \%)$. No outliers of aflatoxins or STC were observed for white rice. The relative standard deviations for repeatability (RSDr) and reproducibility (RSDR) for aflatoxins were 5.7\%-18.6\% and 26.0\%-44.1\%, respectively. A Horwitz ratio (HorRat) value in the range 0.5-2.0 was confirmed at all the spiked levels. Furthermore, values for RSDr, RSDR, and HorRat for STC were 5.2\%-18.9\%, 15.3\%-21.9\%, and 0.4 $(<0.5)$, respectively.

\subsection{Collaborative Validation Results of LC/MS/MS Determination of Aflatoxins and STC in Sorghum}

The results of the interlaboratory study of aflatoxins and STC in sorghum are tabulated in Table 2. The mean ARs for aflatoxins and STC were in the ranges 79\%-99\% and 85\%-97\%, respectively. One outlier was observed in the sorghum sample spiked with $1.0 \mu \mathrm{g} / \mathrm{kg}$ of aflatoxins. The RSDr and RSDR for aflatoxins were in the ranges $8.1 \%-24.4 \%$ and $13.6 \%-42.5 \%$, respectively. The HorRat values of aflatoxins ranged from 0.3 to 1.0. For STC, the AR, RSDr, and RSDR were in the ranges 85\%-97\%, $14.2 \%-29.0 \%$, and $32.0 \%-54.7 \%$, respectively. The HorRat values of STC ranged from 0.8 to 1.0 .

\subsection{Calculation of the Z-Scores}

Eight Korean laboratories participated in the collaborative validation of aflatoxins and STC in white rice and sorghum. Calculation of the Z-scores to evaluate each laboratory's proficiency was based on the results provided by the participating laboratories (Tables 3 and 4). Eight laboratories completed the interlaboratory comparison for aflatoxins and STC successfully. Mean Z-scores were 0.58 and 0.49 for white rice and sorghum, respectively. All Z-scores for aflatoxins in both white rice and STC, which varied from -1.91 to 1.33 , were within the acceptable limits $(|Z| \leq 2)$. The Z-scores reported for STC were within the range -2.19 to 2.82 , with two unsatisfactory data ( -2.19 and 2.82$)$ at the $0.3 \mu \mathrm{g} / \mathrm{kg}$ level.

\subsection{Application of the Validated LC/MS/MS Method to Market Samples}

The validated LC/MS/MS method was used to determine aflatoxins and STC in 20 white rice and 20 sorghum samples sourced from Korean markets. Results are tabulated in Table 5. No rice samples were found to be contaminated with $\mathrm{AFB}_{1}, \mathrm{AFB}_{2}, \mathrm{AFG}_{1}$ or $\mathrm{AFG}_{2}$.

In sorghum samples, $\mathrm{AFB}_{1}$ was detected in $10 \%(2 / 20)$ of samples with values above the LOD. In one sorghum sample, $\mathrm{AFB}_{1}$ was detected between the LOD and limit of quantification (LOQ), and one sample was above the LOQ (detection range $0.1-1.0 \mu \mathrm{g} / \mathrm{kg}$ ). AFG 2 was detected in $15 \%(3 / 20)$ of sorghum samples with values above the LOD. In three samples, it was detected between the LOD and LOQ. No sorghum samples were detected with $\mathrm{AFB}_{2}$ or $\mathrm{AFG}_{1}$.

Regarding STC, it was detected in 70\% (14/20) of white rice samples with values below the LOQ, while in 30\% (6/20) it was detected between the LOD and LOQ. In contrast, STC was detected in only $10 \%(2 / 20)$ of sorghum samples. In two sorghum samples, STC and AFB 1 were detected, but their concentrations were low $(0.1-1.0 \mu \mathrm{g} / \mathrm{kg})$. Furthermore, in one sorghum sample, $\mathrm{STC}, \mathrm{AFB}_{1}, \mathrm{and}_{\mathrm{AFG}}$ were detected simultaneously. 
Table 1. Collaborative validation results of liquid chromatography-tandem mass spectrometry (LC/MS/MS) determination of aflatoxins and sterigmatocystin (STC) in white rice.

\begin{tabular}{|c|c|c|c|c|c|c|c|c|c|c|c|c|c|c|c|}
\hline \multirow{3}{*}{ Laboratory } & \multicolumn{15}{|c|}{ Spiked Samples $(\mu \mathrm{g} / \mathrm{kg})$} \\
\hline & \multicolumn{3}{|c|}{$\mathrm{AFB}_{1}{ }^{a}$} & \multicolumn{3}{|c|}{$\mathrm{AFB}_{2} b$} & \multicolumn{3}{|c|}{$\mathrm{AFG}_{1} c$} & \multicolumn{3}{|c|}{$\mathrm{AFG}_{2}{ }^{d}$} & \multicolumn{3}{|c|}{$\operatorname{STC}^{e}$} \\
\hline & 1.0 & 2.5 & 5.0 & 1.0 & 2.5 & 5.0 & 1.0 & 2.5 & 5.0 & 2.0 & 5.0 & 10.0 & 0.30 & 0.75 & 1.50 \\
\hline 1 & 1.09 & 2.54 & 5.02 & 1.08 & 2.55 & 5.13 & 1.07 & 2.54 & 5.03 & 2.00 & 5.06 & 10.78 & 0.30 & 0.71 & 1.55 \\
\hline 2 & 0.69 & 1.51 & 3.24 & 0.87 & 1.67 & 3.58 & 0.62 & 1.56 & 3.13 & 1.41 & 3.01 & 6.48 & 0.26 & 0.61 & 1.19 \\
\hline 3 & 0.76 & 1.96 & 3.96 & 0.76 & 1.89 & 3.85 & 0.63 & 1.80 & 3.71 & 1.38 & 3.23 & 7.04 & 0.29 & 0.69 & 1.37 \\
\hline 4 & 0.95 & 2.56 & 4.68 & 0.98 & 2.57 & 4.99 & 0.91 & 2.14 & 3.86 & 1.73 & 3.05 & 7.65 & 0.22 & 0.65 & 1.24 \\
\hline 5 & 0.99 & 2.43 & 4.76 & 1.04 & 2.54 & 4.90 & 0.95 & 2.48 & 4.98 & 2.10 & 5.26 & 9.93 & 0.28 & 0.68 & 1.35 \\
\hline 6 & 1.01 & 2.63 & 5.02 & 0.95 & 2.58 & 5.14 & 1.04 & 2.72 & 5.40 & 2.03 & 5.17 & 10.37 & 0.29 & 0.70 & 1.38 \\
\hline 7 & 0.69 & 1.78 & 3.91 & 0.49 & 1.53 & 3.74 & 0.60 & 1.58 & 3.77 & 1.28 & 2.72 & 6.94 & 0.34 & 0.75 & 1.55 \\
\hline 8 & 1.13 & 2.84 & 5.65 & 1.11 & 2.79 & 5.70 & 1.08 & 2.71 & 5.27 & 2.03 & 5.26 & 11.10 & 0.33 & 0.80 & 1.53 \\
\hline Mean $(\mu \mathrm{g} / \mathrm{kg})$ & 0.91 & 2.28 & 4.53 & 0.91 & 2.27 & 4.63 & 0.86 & 2.19 & 4.39 & 1.75 & 4.10 & 8.79 & 0.29 & 0.70 & 1.39 \\
\hline $\operatorname{AR}(\%)^{f}$ & 91.0 & 91.2 & 90.6 & 91.0 & 90.8 & 92.6 & 86.0 & 87.6 & 87.8 & 87.5 & 82.0 & 87.9 & 96.7 & 93.3 & 92.7 \\
\hline Outlier 8 & 0 & 0 & 0 & 0 & 0 & 0 & 0 & 0 & 0 & 0 & 0 & 0 & 0 & 0 & 0 \\
\hline $\operatorname{RSD}_{\mathrm{r}}(\%)^{h}$ & 16.4 & 5.7 & 9.3 & 16.9 & 13.4 & 7.3 & 18.1 & 15.6 & 9.4 & 18.6 & 13.3 & 10.9 & 15.9 & 18.9 & 5.2 \\
\hline $\operatorname{RSDR}(\%)^{i}$ & 31.2 & 31.2 & 26.5 & 35.9 & 33.7 & 26.0 & 39.1 & 35.4 & 30.3 & 32.1 & 44.1 & 34.0 & 21.9 & 18.4 & 15.3 \\
\hline HorRat & 0.7 & 0.8 & 0.7 & 0.8 & 0.9 & 0.7 & 0.9 & 0.9 & 0.9 & 0.8 & 1.2 & 1.1 & 0.4 & 0.4 & 0.4 \\
\hline
\end{tabular}

a $\mathrm{AFB}_{1}$ : aflatoxin $\mathrm{B}_{1} ;{ }^{b} \mathrm{AFB}_{2}$ : aflatoxin $\mathrm{B}_{2} ;{ }^{c} \mathrm{AFG}_{1}$ : aflatoxin $\mathrm{G}_{1} ;{ }^{d} \mathrm{AFG}_{2}$ : aflatoxin $\mathrm{G}_{2} ;{ }^{e}$ STC: sterigmatocystin; ${ }^{f}$ AR: apparent recovery; ${ }^{g}$ Outlier: cochran and single Grubbs parameters;

${ }^{h} \mathrm{RSD}_{\mathrm{r}}$ : relative standard deviation of repeatability; ${ }^{i} \mathrm{RSDR}$ : relative standard deviation of reproducibility. 
Table 2. Collaborative validation results of LC/MS/MS determination of aflatoxins and STC in sorghum.

\begin{tabular}{|c|c|c|c|c|c|c|c|c|c|c|c|c|c|c|c|}
\hline \multirow{3}{*}{ Laboratory } & \multicolumn{15}{|c|}{ Spiked Samples ( $\mu \mathrm{g} / \mathrm{kg})$} \\
\hline & \multicolumn{3}{|c|}{$\mathrm{AFB}_{1}{ }^{a}$} & \multicolumn{3}{|c|}{$\mathrm{AFB}_{2} b$} & \multicolumn{3}{|c|}{$\mathrm{AFG}_{1} c$} & \multicolumn{3}{|c|}{$\mathrm{AFG}_{2}{ }^{d}$} & \multicolumn{3}{|c|}{$\mathrm{STC}^{e}$} \\
\hline & 1.0 & 2.5 & 5.0 & 1.0 & 2.5 & 5.0 & 1.0 & 2.5 & 5.0 & 2.0 & 5.0 & 10.0 & 0.30 & 0.75 & 1.50 \\
\hline 1 & 1.00 & 2.44 & 4.64 & 0.89 & 2.04 & 4.79 & 0.95 & 2.24 & 4.77 & 1.81 & 4.26 & 9.50 & 0.21 & 0.51 & 1.06 \\
\hline 2 & 1.03 & 1.69 & 2.87 & 0.74 & 1.55 & 2.94 & 0.79 & 1.71 & 2.98 & 2.22 & 3.50 & 6.03 & 0.14 & 0.35 & 0.76 \\
\hline 3 & 1.10 & 2.39 & 4.56 & 0.93 & 2.22 & 4.23 & 1.01 & 2.25 & 4.31 & 0.82 & 3.38 & 7.67 & 0.27 & 0.65 & 1.45 \\
\hline 4 & 0.62 & 1.84 & 3.49 & 0.71 & 1.86 & 4.46 & 0.58 & 2.46 & 4.24 & 1.28 & 3.96 & 9.18 & 0.25 & 0.66 & 1.35 \\
\hline 5 & 0.90 & 2.35 & 4.88 & 0.93 & 2.19 & 4.88 & 0.89 & 2.23 & 4.68 & 1.87 & 4.31 & 9.36 & 0.30 & 0.72 & 1.46 \\
\hline 6 & 1.04 & 2.62 & 5.40 & 1.07 & 2.57 & 5.42 & 1.01 & 2.55 & 5.68 & 2.01 & 4.75 & 10.34 & 0.32 & 0.76 & 1.56 \\
\hline 7 & 0.97 & 1.94 & 3.96 & 0.93 & 1.83 & 4.04 & 0.50 & 1.43 & 3.63 & 1.54 & 3.04 & 7.10 & 0.47 & 0.72 & 1.23 \\
\hline 8 & 0.92 & 2.37 & 3.95 & 0.92 & 2.42 & 3.46 & 0.91 & 2.32 & 3.48 & 1.65 & 4.31 & 6.38 & 0.33 & 0.77 & 1.39 \\
\hline Mean $(\mu \mathrm{g} / \mathrm{kg})$ & 0.99 & 2.21 & 4.22 & 0.89 & 2.08 & 4.28 & 0.83 & 2.15 & 4.22 & 1.65 & 3.94 & 8.19 & 0.29 & 0.64 & 1.28 \\
\hline $\operatorname{AR}(\%)^{f}$ & 99.0 & 88.4 & 84.4 & 89.0 & 83.2 & 85.6 & 83.0 & 86.0 & 84.4 & 82.5 & 78.8 & 81.9 & 96.7 & 85.3 & 85.3 \\
\hline Outlier 8 & 1 & 0 & 0 & 0 & 0 & 0 & 0 & 0 & 0 & 0 & 0 & 0 & 0 & 0 & 0 \\
\hline $\operatorname{RSD}_{\mathrm{r}}(\%)^{h}$ & 11.9 & 14.6 & 8.1 & 18.3 & 17.4 & 9.6 & 21.6 & 14.6 & 17.4 & 19.3 & 24.4 & 12.8 & 29.0 & 24.2 & 14.2 \\
\hline $\operatorname{RSDR}(\%)^{i}$ & 13.6 & 24.8 & 29.4 & 23.0 & 26.9 & 28.8 & 38.5 & 28.6 & 32.7 & 42.5 & 28.1 & 30.8 & 54.7 & 38.0 & 32.0 \\
\hline HorRat & 0.3 & 0.6 & 0.8 & 0.5 & 0.7 & 0.8 & 0.9 & 0.7 & 0.9 & 1.0 & 0.8 & 1.0 & 1.0 & 0.8 & 0.8 \\
\hline
\end{tabular}

${ }^{a} \mathrm{AFB}_{1}$ : aflatoxin $\mathrm{B}_{1} ;{ }^{b} \mathrm{AFB}_{2}$ : aflatoxin $\mathrm{B}_{2} ;{ }^{c} \mathrm{AFG}_{1}$ : aflatoxin $\mathrm{G}_{1} ;{ }^{d} \mathrm{AFG}_{2}$ : aflatoxin $\mathrm{G}_{2} ;{ }^{e}$ STC: sterigmatocystin; ${ }^{f}$ AR: apparent recovery; ${ }^{g}$ Outlier: cochran and single Grubbs parameters ${ }^{h} \mathrm{RSD}_{\mathrm{r}}$ : relative standard deviation of repeatability; ${ }^{i} \mathrm{RSDR}$ : relative standard deviation of reproducibility. 
Table 3. Results of mycotoxin analysis and relevant scoring in white rice.

\begin{tabular}{|c|c|c|c|c|c|c|c|c|c|}
\hline \multirow{2}{*}{ Toxins } & \multirow{2}{*}{$\begin{array}{c}\text { Assigned Values } \\
(\mu \mathrm{g} / \mathrm{kg})\end{array}$} & \multicolumn{8}{|c|}{ Laboratory } \\
\hline & & 1 & 2 & 3 & 4 & 5 & 6 & 7 & 8 \\
\hline \multirow{3}{*}{$\mathrm{AFB}_{1}{ }^{a}$} & 1 & 0.79 & -1.03 & -0.70 & 0.16 & 0.34 & 0.43 & -1.00 & 0.99 \\
\hline & 2.5 & 0.47 & -1.40 & -0.57 & 0.50 & 0.27 & 0.63 & -0.91 & 1.02 \\
\hline & 5 & 0.45 & -1.17 & -0.52 & 0.13 & 0.21 & 0.45 & -0.56 & 1.02 \\
\hline \multirow{3}{*}{$\mathrm{AFB}_{2}{ }^{b}$} & 1 & 0.76 & -0.18 & -0.70 & 0.32 & 0.61 & 0.19 & -1.91 & 0.92 \\
\hline & 2.5 & 0.52 & -1.08 & -0.69 & 0.56 & 0.50 & 0.58 & -1.34 & 0.96 \\
\hline & 5 & 0.46 & -0.95 & -0.71 & 0.33 & 0.25 & 0.46 & -0.80 & 0.97 \\
\hline \multirow{3}{*}{$\mathrm{AFG}_{1}{ }^{c}$} & 1 & 0.95 & -1.12 & -1.05 & 0.23 & 0.40 & 0.82 & -1.20 & 0.97 \\
\hline & 2.5 & 0.64 & -1.14 & -0.71 & -0.09 & 0.52 & 0.96 & -1.12 & 0.95 \\
\hline & 5 & 0.58 & -1.15 & -0.62 & -0.48 & 0.54 & 0.91 & -0.57 & 0.79 \\
\hline \multirow{3}{*}{$\mathrm{AFG}_{2}{ }^{d}$} & 2 & 0.58 & -0.77 & -0.82 & -0.04 & 0.80 & 0.64 & -1.05 & 0.65 \\
\hline & 5 & 0.87 & -0.98 & -0.78 & -0.95 & 1.06 & 0.98 & -1.25 & 1.06 \\
\hline & 10 & 0.91 & -1.05 & -0.80 & -0.51 & 0.52 & 0.72 & -0.84 & 1.05 \\
\hline \multirow{3}{*}{$\mathrm{STC}^{e}$} & 0.3 & 0.17 & -0.40 & -0.05 & -0.98 & -0.09 & -0.01 & 0.79 & 0.57 \\
\hline & 0.75 & 0.04 & -0.54 & -0.03 & -0.32 & -0.10 & 0.02 & 0.31 & 0.63 \\
\hline & 1.5 & 0.48 & -0.61 & -0.08 & -0.46 & -0.15 & -0.05 & 0.47 & 0.40 \\
\hline
\end{tabular}

${ }^{a} \mathrm{AFB}_{1}$ : aflatoxin $\mathrm{B}_{1} ;{ }^{b} \mathrm{AFB}_{2}$ : aflatoxin $\mathrm{B}_{2} ;{ }^{c} \mathrm{AFG}_{1}$ : aflatoxin $\mathrm{G}_{1} ;{ }^{d} \mathrm{AFG}_{2}$ : aflatoxin $\mathrm{G}_{2} ;{ }^{e} \mathrm{STC}$ : sterigmatocystin.

Table 4. Results of mycotoxin analysis and relevant scoring in sorghum.

\begin{tabular}{|c|c|c|c|c|c|c|c|c|c|}
\hline \multirow{2}{*}{ Toxins } & \multirow{2}{*}{$\begin{array}{c}\text { Assigned Values } \\
(\mu \mathrm{g} / \mathrm{kg})\end{array}$} & \multicolumn{8}{|c|}{ Laboratory } \\
\hline & & 1 & 2 & 3 & 4 & 5 & 6 & 7 & 8 \\
\hline \multirow{3}{*}{$\mathrm{AFB}_{1}{ }^{a}$} & 1 & 0.26 & 0.38 & 0.69 & -1.50 & -0.23 & 0.41 & 0.11 & -0.12 \\
\hline & 2.5 & 0.43 & -0.93 & 0.34 & -0.66 & 0.26 & 0.75 & -0.48 & 0.30 \\
\hline & 5 & 0.38 & -1.22 & 0.31 & -0.66 & 0.60 & 1.07 & -0.24 & -0.25 \\
\hline \multirow{3}{*}{$\mathrm{AFB}_{2} b$} & 1 & 0.02 & -0.68 & 0.17 & -0.80 & 0.17 & 0.80 & 0.16 & 0.15 \\
\hline & 2.5 & -0.09 & -0.97 & 0.24 & -0.41 & 0.20 & 0.88 & -0.46 & 0.60 \\
\hline & 5 & 0.47 & -1.22 & -0.04 & 0.17 & 0.54 & 1.04 & -0.21 & -0.74 \\
\hline \multirow{3}{*}{$\mathrm{AFG}_{1}{ }^{c}$} & 1 & 0.54 & -0.19 & 0.84 & -1.14 & 0.27 & 0.82 & -1.52 & 0.38 \\
\hline & 2.5 & 0.17 & -0.79 & 0.18 & 0.57 & 0.15 & 0.73 & -1.31 & 0.31 \\
\hline & 5 & 0.50 & -1.13 & 0.08 & 0.02 & 0.42 & 1.33 & -0.54 & -0.67 \\
\hline \multirow{3}{*}{$\mathrm{AFG}_{2}{ }^{d}$} & 2 & 0.36 & 1.31 & -1.89 & -0.84 & 0.50 & 0.82 & -0.25 & 0.00 \\
\hline & 5 & 0.29 & -0.40 & -0.51 & 0.01 & 0.34 & 0.74 & -0.82 & 0.34 \\
\hline & 10 & 0.59 & -0.98 & -0.24 & 0.45 & 0.53 & 0.98 & -0.50 & -0.82 \\
\hline \multirow{3}{*}{$\mathrm{STC}^{e}$} & $0.3^{f}$ & -1.17 & -2.19 & -0.32 & -0.49 & 0.25 & 0.51 & 2.82 & 0.60 \\
\hline & 0.75 & -0.81 & -1.79 & 0.06 & 0.12 & 0.47 & 0.71 & 0.44 & 0.79 \\
\hline & 1.5 & -0.67 & -1.57 & 0.50 & 0.19 & 0.55 & 0.84 & -0.17 & 0.33 \\
\hline
\end{tabular}

${ }^{a} \mathrm{AFB}_{1}$ : aflatoxin $\mathrm{B}_{1} ;{ }^{b} \mathrm{AFB}_{2}$ : aflatoxin $\mathrm{B}_{2} ;{ }^{c} \mathrm{AFG}_{1}$ : aflatoxin $\mathrm{G}_{1} ;{ }^{d} \mathrm{AFG}_{2}$ : aflatoxin $\mathrm{G}_{2} ;{ }^{e}$ STC: sterigmatocystin;

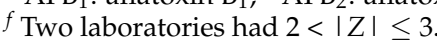


Table 5. Application of validated LC/MS/MS for determination of aflatoxins and sterigmatocystin in rice and sorghum samples sourced from Korean markets.

\begin{tabular}{|c|c|c|c|c|c|c|c|}
\hline \multirow{2}{*}{ Myotoxin } & \multirow{2}{*}{ Product } & \multirow{2}{*}{ Sample } & \multicolumn{3}{|c|}{ Number of Samples } & \multicolumn{2}{|c|}{$\begin{array}{c}\text { Concentration Range }{ }^{h} \\
(\mu \mathrm{g} / \mathrm{kg})\end{array}$} \\
\hline & & & $<\operatorname{LOD}^{f}$ & LOD-LOQ $^{g}$ & $>$ LOQ & $0.1 \sim 1.0$ & $1.0 \sim 2.0$ \\
\hline \multirow{2}{*}{$\mathrm{AFB}_{1} a$} & Rice & 20 & $20(100)^{i}$ & - & - & - & - \\
\hline & Sorghum & 20 & $18(90)$ & $1(5)$ & $1(5)$ & $2(10)$ & - \\
\hline \multirow{2}{*}{$\mathrm{AFB}_{2}{ }^{b}$} & Rice & 20 & $20(100)$ & - & - & - & - \\
\hline & Sorghum & 20 & $20(100)$ & - & - & - & - \\
\hline \multirow{2}{*}{$\mathrm{AFG}_{1}{ }^{c}$} & Rice & 20 & $20(100)$ & - & - & - & - \\
\hline & Sorghum & 20 & $20(100)$ & - & - & - & - \\
\hline \multirow{2}{*}{$\mathrm{AFG}_{2}{ }^{d}$} & Rice & 20 & $20(100)$ & - & - & - & - \\
\hline & Sorghum & 20 & $17(85)$ & $3(15)$ & - & - & - \\
\hline \multirow{2}{*}{$\mathrm{STC}^{e}$} & Rice & 20 & $14(70)$ & $6(30)$ & - & - & - \\
\hline & Sorghum & 20 & - & $18(90)$ & $2(10)$ & $2(10)$ & - \\
\hline
\end{tabular}

${ }^{a} \mathrm{AFB}_{1}$ : aflatoxin $\mathrm{B}_{1} ;{ }^{b} \mathrm{AFB}_{2}$ : aflatoxin $\mathrm{B}_{2} ;{ }^{c} \mathrm{AFG}_{1}$ : aflatoxin $\mathrm{G}_{1} ;{ }^{d} \mathrm{AFG}_{2}$ : aflatoxin $\mathrm{G}_{2} ;{ }^{e} \mathrm{STC}$ : sterigmatocystin;

${ }^{f}$ LOD: limit of detection; ${ }^{g}$ LOQ: limit of quantification; ${ }^{h} \mathrm{AF}$ concentration was not corrected for the AR result;

${ }^{i}$ Figure in parenthesis indicates percentage.

\section{Discussion}

This study describes a harmonized collaborative validation of multiple mycotoxin detection in white rice and sorghum using LC/MS/MS. We found that the LC/MS/MS method possessed the performance characteristics required to obtain accurate results. In the case of white rice spiked with $1.0-10.0 \mu \mathrm{g} / \mathrm{kg}$ aflatoxins, the mean AR ( $82 \%-91 \%)$, and the values obtained for RSDr $(5.7 \%-18.6 \%)$ and RSDR $(26.5 \%-44.1 \%)$ were considered acceptable, taking into consideration the performance criteria (AR $70 \%-110 \%$ and $\mathrm{RSD}_{\mathrm{R}} \leq 45.2 \%$ ) suggested by EU guidelines for aflatoxins [33]. The RSDR value $(44.1 \%)$ of $\mathrm{AFG}_{2}$ spiked samples $(5.0 \mu \mathrm{g} / \mathrm{kg})$ was close to the maximum value stated by the EU guidelines. It might be caused by the sample-to-sample variation of matrix effects or the inter-laboratory variability result from different technical expertise and established workflows for individual laboratories. The important expression of the method's precision is the HorRat value, which is calculated as a ratio of \%RSDR to the predicted reproducibility RSD, \%PRSDR. The \%PRSDR is a function of the analyte concentration and is expressed as $2 C^{-0.1505}$, where $C$ is the estimated mean concentration [24]. In comparison with AOAC guidelines [24], a HorRat value in the range 0.5-2.0 was confirmed for white rice at all the spiked levels. This indicated that the presented method was reproducible for the determination of aflatoxins contained in white rice. HorRat values of STC were $0.4(<0.5)$. Consistent deviations from the ratio that were on the low side (values $<0.5)$ may indicate unreported averaging or excellent training and experience [34].

For spiked sorghum, all parameters of aflatoxins satisfied the criteria mentioned [33] above, although one outlier $(0.62 \mu \mathrm{g} / \mathrm{kg})$ was observed in the $\mathrm{AFB}_{1}$ result at the $1.0 \mu \mathrm{g} / \mathrm{kg}$ level. Results also showed a HorRat value of 0.3 at the $1.0 \mu \mathrm{g} / \mathrm{kg}$ level of $\mathrm{AFB}_{1}$ in sorghum. However, no problems were recognized throughout this interlaboratory study, suggesting that outliers may have been due to random errors. It was also noticeable that the ARs of aflatoxins and STC in sorghum were slightly lower than they were in white rice, perhaps due to the matrix suppression effect of sorghum.

Calculation of the Z-scores suggested that all eight laboratories completed the interlaboratory comparison successfully. Unsatisfactory Z-scores for STC from individual laboratories were mainly a consequence of low or high ARs.

In summarizing information on analytical methods for STC in foodstuffs, Veršilovskis and de Saeger [19] concluded that LC/MS/MS should be used in efforts to develop sensitive methods and that sample preparation should be improved. This was realized in some new methods developed for the determination of STC in various grains and cheese by Veršilovskis et al. (LOD $0.03-0.15 \mu \mathrm{g} / \mathrm{kg}$ ) $[20,35]$ and in the multi-mycotoxin method reported by Sulyok et al. (LOD $0.4 \mu \mathrm{g} / \mathrm{kg}$ ) [29]. Furthermore, Goto 
and co-workers [36] developed a new method for analyzing STC in grains using an immunoaffinity column (IAC) and LC/MS. This method is effective for STC analysis in grains and holds potential for a new application of a commercial IAC in STC analysis of aflatoxins. Based on EU guidelines, the AR, repeatability, and reproducibility levels were acceptable. Hence, this method should be useful for future studies on the occurrence and risk attached to aflatoxins and STC.

In our study, the validated LC/MS/MS method was successfully applied for the analysis of natural samples sourced from Korean markets. The results showed a low occurrence of aflatoxins in both white rice and sorghum samples, with no sample exceeding the EU maximum limits for aflatoxins $(<2 \mu \mathrm{g} / \mathrm{kg})[17,18]$. $\mathrm{AFB}_{1}$ and $\mathrm{AFG}_{2}$ with concentrations $>$ LOD values were only detected in sorghum samples. In contrast, the incidence of STC with concentrations $<$ LOD values was high in sorghum samples, but their concentrations were low $(0.1-1.0 \mu \mathrm{g} / \mathrm{kg})$. Of particular importance was the simultaneous detection of $\mathrm{STC}, \mathrm{AFB}_{1}$, and $\mathrm{AFG}_{2}$ in a sorghum sample.

\section{Conclusions}

Harmonized collaborative validation of aflatoxins and STC in white rice and sorghum was carried out using LC/MS/MS. The HorRat value was $<1.5$, which indicates that the method described in this study is reproducible for the determination of aflatoxins and STC contained in both white rice and sorghum at concentrations in the range $0.3-10.0 \mu \mathrm{g} / \mathrm{kg}$. Currently, no country has legislation for STC. As aflatoxins and STC are naturally occurring substances, it is important to gather further information regarding suitable analytical methods for their detection. Our results indicate that the validated LC/MS/MS method described here can be successfully applied for the determination of aflatoxins and STC that naturally contaminate white rice and sorghum.

\section{Materials and Methods}

\subsection{Reagents and Chemicals}

Formic acid (LC/MS grade) was purchased from Fisher Scientific (Geel, Belgium). Water, acetonitrile, and methanol (HPLC grade) were purchased from J.T. Baker (Phillipsburg, NJ, USA). Mycotoxin solid standards $\mathrm{AFB}_{2}\left(5 \mathrm{mg}\right.$, Lot No. A9887), $\mathrm{AFG}_{1}$ (1 mg, Lot No. A0138), and $\mathrm{AFG}_{2}$ (5 mg, Lot No. A0263) were purchased from Sigma-Aldrich (St. Louis, MO, USA). AFB 1 $(2.01 \mu \mathrm{g} / \mathrm{mL}$ in acetonitrile, Lot No. L15153A) and STC (50.2 $\mu \mathrm{g} / \mathrm{mL}$ in acetonitrile, Lot No. L14424S) were purchased from Romer Labs (Tulln, Austria). For each aflatoxin and STC standard, a stock solution of $100 \mathrm{ng} / \mathrm{mL}$ was prepared in acetonitrile and stored at $-20{ }^{\circ} \mathrm{C}$. The aflatoxin solutions were calibrated spectrophotometrically at $350 \mathrm{~nm}$, using the method published by the association of analytical communities (AOAC) [37]. Aflatoxins and STC working standard solutions were prepared by evaporating an exact volume of stock solution under nitrogen gas and re-dissolving the residue in acetonitrile to reach a final concentration of $10 \mathrm{ng} / \mathrm{mL}$ for $\mathrm{AFB}_{1}, \mathrm{AFB}_{2}$ and $\mathrm{AFG}_{1}, 20 \mathrm{ng} / \mathrm{mL}$ for $\mathrm{AFG}_{2}$, and $3 \mathrm{ng} / \mathrm{mL}$ for STC, respectively.

\subsection{Interlaboratory Study Design}

Eight laboratories in Korea participated in this interlaboratory study to validate the method. The same aflatoxin and STC free samples of white rice and sorghum that were previously examined by a laboratory were spiked with aflatoxin and STC standard solutions to reach a final concentration of 1 , 2.5 and $5 \mu \mathrm{g} / \mathrm{kg}$ for $\mathrm{AFB}_{1}, \mathrm{AFB}_{2}, \mathrm{AFG}_{1}$ and $\mathrm{AFG}_{2}$, and $0.3,0.75$ and $1.5 \mu \mathrm{g} / \mathrm{kg}$ for STC, respectively. All spiked samples were prepared by the organizer's laboratory and sent to each participating laboratory for analysis. Each participant was supplied with three bottles of blank white rice and sorghum samples, and three bottles of spiked (3 levels) white rice and sorghum samples. 


\subsection{Sample Extraction}

A spiked $5 \mathrm{~g}$ sample was placed in a $50 \mathrm{~mL}$ conical tube with $20 \mathrm{~mL}$ of extract solution (acetonitrile/water, 50:50, $v / v$ containing $0.1 \%$ formic acid) and placed on a vortex shaker for $5 \mathrm{~min}$. After extraction, the sample was centrifuged at $3500 \mathrm{rpm}$ for $5 \mathrm{~min}$ and then filtered through glass microfiber filter paper (GF/A grade, $110 \mathrm{~mm}$; Whatman, Little Chalfont, UK). A $4 \mathrm{~mL}$ volume of filtrate extract was diluted with $16 \mathrm{~mL}$ water. An SPE column (ISOLUTE ${ }^{\circledR}$ Myco, $60 \mathrm{mg} / 3 \mathrm{~mL}$; Biotage, Cardiff, UK) was preconditioned with $2 \mathrm{~mL}$ acetonitrile and then $2 \mathrm{~mL}$ water. Five milliliters of dilute solution were applied to the SPE column, followed by washing with $2 \mathrm{~mL}$ water and then $2 \mathrm{~mL}$ acetonitrile/water $(10: 90, v / v)$. The toxins that remained on the column were eluted with $4 \mathrm{~mL}$ acetonitrile. The collected eluate was evaporated with $\mathrm{N}_{2}$ gas under vacuum at $50{ }^{\circ} \mathrm{C}$. The residue was dissolved in $1 \mathrm{~mL}$ acetonitrile/water (50:50, $v / v)$ and then filtered through a polyvinylidene fluoride syringe filter $(0.2 \mu \mathrm{m}$; Whatman, Pittsburgh, PA, USA).

\subsection{Calibration Solutions}

Aflatoxins and STC free samples of white rice and sorghum were used for the manufacture of matrix-matched calibration curves. Sample solutions were prepared using the same method described in sample extraction. Standard solution of mycotoxin was added into sample solution to reach different concentrations $\left(0.5,1.0,2.5,5.0,10.0 \mu \mathrm{g} / \mathrm{kg}\right.$ for $\mathrm{AFB}_{1}, \mathrm{AFB}_{2}$, and $\mathrm{AFG}_{1} ; 1.0,2.0,5.0,10.0,20.0 \mu \mathrm{g} / \mathrm{kg}$ for $\mathrm{AFG}_{2}$; and $0.15,0.30,0.75,1.50,3.00 \mu \mathrm{g} / \mathrm{kg}$ for STC, respectively). Calibration solutions were prepared by the organizer's laboratory and sent to each participating laboratory for analysis. The concentrations of aflatoxins and STC in the sample solutions were calculated from calibration curves. The LOD and LOQ were calculated using the slope $(b)$ of the matrix calibration curve and the residual standard error $\left(s_{y / x}\right)$ with the following equations [38]: LOD $=3.3 s_{y / x} / b ; \mathrm{LOQ}=10 s_{y / x} / b$. The LOQ for $\mathrm{AFB}_{1}, \mathrm{AFB}_{2}$, $\mathrm{AFG}_{1}, \mathrm{AFG}_{2}$, and STC was $0.28,0.35,0.42,0.90$, and $0.52 \mu \mathrm{g} / \mathrm{kg}$, respectively.

\subsection{LC/MS/MS Analysis}

Each laboratory determined the aflatoxins and STC concentrations by LC/MS/MS. Two microliters of the final solution were loaded on an XBbridge C18 column $(1.7 \mu \mathrm{m}, 2.1 \times 100 \mathrm{~mm}$; Waters, Milford, MA, USA) at $35^{\circ} \mathrm{C}$. Gradient elution was carried out with mixtures of acetonitrile and water (see Table 6). Electrospray ionization in the positive mode was used. Multiple reactions monitoring (MRM) mode was used here with LC/MS/MS. All other experimental conditions were set by the respective participating laboratories. LC/MS/MS instruments and parameters used in the eight participating laboratories are tabulated in Table 7. Supplementary material, describing chromatograms of each mycotoxin detected by LC/MS/MS in MRM mode, is available (Figure S1).

Table 6. Analysis of aflatoxins and sterigmatocystin residues by LC/MS/MS.

\begin{tabular}{ccc}
\hline Time, $\min ^{\boldsymbol{a}}$ & $\mathbf{A ,} \mathbf{\%}^{\boldsymbol{b}}$ & $\mathbf{B}, \boldsymbol{\%}^{\boldsymbol{c}}$ \\
\hline 0.0 & 90 & 10 \\
3.0 & 90 & 10 \\
10.0 & 30 & 70 \\
10.1 & 10 & 90 \\
12.0 & 10 & 90 \\
12.1 & 90 & 10 \\
15.0 & 90 & 10
\end{tabular}

${ }^{a}$ Flow rate, $0.2 \mathrm{~mL} / \mathrm{min} ;{ }^{b}$ Mobile phase A, $0.1 \%$ formic acid in water; ${ }^{c}$ Mobile phase $\mathrm{B}, 0.1 \%$ formic acid in acetonitrile. 
Table 7. LC/MS/MS instruments and parameters used in the eight participating laboratories.

\begin{tabular}{|c|c|c|c|c|c|c|c|c|c|c|c|}
\hline \multirow[b]{2}{*}{ Lab. } & \multirow[b]{2}{*}{ LC-MS/MS Equipment } & \multicolumn{2}{|c|}{$\mathrm{AFB}_{1}{ }^{a}$} & \multicolumn{2}{|c|}{$\mathrm{AFB}_{2}{ }^{b}$} & \multicolumn{2}{|c|}{$\mathrm{AFG}_{1}{ }^{c}$} & \multicolumn{2}{|c|}{$\mathrm{AFG}_{2}{ }^{\mathrm{d}}$} & \multicolumn{2}{|c|}{$\mathrm{STC}^{e}$} \\
\hline & & $\begin{array}{l}\text { Precursor } \\
\text { Ion }(m / z)\end{array}$ & $\begin{array}{l}\text { Product } \\
\text { Ion }(m / z) f\end{array}$ & $\begin{array}{l}\text { Precursor } \\
\text { Ion }(\mathrm{m} / \mathrm{z})\end{array}$ & $\begin{array}{l}\text { Product } \\
\text { Ion }(m / z)\end{array}$ & $\begin{array}{l}\text { Precursor } \\
\text { Ion }(m / z)\end{array}$ & $\begin{array}{l}\text { Product } \\
\text { Ion }(m / z)\end{array}$ & $\begin{array}{l}\text { Precursor } \\
\text { Ion }(m / z)\end{array}$ & $\begin{array}{l}\text { Product } \\
\text { Ion }(\mathrm{m} / \mathrm{z})\end{array}$ & $\begin{array}{l}\text { Precursor } \\
\text { Ion }(m / z)\end{array}$ & $\begin{array}{l}\text { Product } \\
\text { Ion }(m / z)\end{array}$ \\
\hline 1 & $\begin{array}{l}\text { ThermoAccela TSQ Quantum Ultra } \\
\text { (Thermo Scientific, Waltham, MA, USA) }\end{array}$ & \multirow{8}{*}{$\begin{array}{c}313.0 \\
{[\mathrm{M}+\mathrm{H}]^{+}}\end{array}$} & 284.9 & \multirow{8}{*}{$\begin{array}{c}315.0 \\
{[\mathrm{M}+\mathrm{H}]^{+}}\end{array}$} & 287.0 & \multirow{8}{*}{$\begin{array}{c}329.1 \\
{[\mathrm{M}+\mathrm{H}]^{+}}\end{array}$} & 311.0 & \multirow{8}{*}{$\begin{array}{c}331.1 \\
{[\mathrm{M}+\mathrm{H}]^{+}}\end{array}$} & 313.0 & \multirow{8}{*}{$\begin{array}{c}325.1 \\
{[\mathrm{M}+\mathrm{H}]^{+}}\end{array}$} & 310.0 \\
\hline 2 & $\begin{array}{l}\text { HPLC coupled with TSQ Quantum } \\
\text { (Thermo Scientific, Waltham, MA, USA) }\end{array}$ & & 241.1 & & 259.0 & & 199.8 & & 245.0 & & 310.0 \\
\hline 3 & $\begin{array}{l}\text { ThermoAccela TSQ Quantum Ultra } \\
\text { (Thermo Scientific, Waltham, MA, USA) }\end{array}$ & & 284.9 & & 287.0 & & 311.0 & & 313.0 & & 310.0 \\
\hline 4 & $\begin{array}{l}\text { Acquity I-class UPLC Xevo TQ-S } \\
\text { (Waters, Milford, MA, USA) }\end{array}$ & & 241.1 & & 259.0 & & 199.8 & & 245.0 & & 310.0 \\
\hline 5 & $\begin{array}{l}\text { Acquity I-class UPLC Xevo TQ-2 } \\
\text { (Waters, Milford, MA, USA) }\end{array}$ & & 284.9 & & 287.0 & & 243.0 & & 245.0 & & 281.0 \\
\hline 6 & $\begin{array}{l}\text { ThermoAccela TSQ Quantum Ultra } \\
\text { (Thermo Scientific, Waltham, MA, USA) }\end{array}$ & & 284.9 & & 287.0 & & 311.0 & & 313.0 & & 310.0 \\
\hline 7 & $\begin{array}{l}\text { Acquity I-class UPLC Xevo TQ-S } \\
\text { (Waters, Milford, MA, USA) }\end{array}$ & & 241.1 & & 259.0 & & 199.8 & & 245.0 & & 310.0 \\
\hline 8 & $\begin{array}{l}\text { Acquity I-class UPLC Xevo TQ-2 } \\
\text { (Waters, Milford, MA, USA) }\end{array}$ & & 241.1 & & 259.0 & & 199.8 & & 245.0 & & 310.0 \\
\hline
\end{tabular}

${ }^{a} \mathrm{AFB}_{1}$ : aflatoxin $\mathrm{B}_{1} ;{ }^{b} \mathrm{AFB}_{2}$ : aflatoxin $\mathrm{B}_{2} ;{ }^{c} \mathrm{AFG}_{1}$ : aflatoxin $\mathrm{G}_{1} ;{ }^{d} \mathrm{AFG}_{2}$ : aflatoxin $\mathrm{G}_{2} ;{ }^{e}$ STC: sterigmatocystin; ${ }^{f}$ In addition to the product ion selected in each laboratory for quantification. 


\subsection{Statistical Analysis}

The results received from the participating laboratories were initially evaluated for evidence of outliers using the following statistical tests: the Cochran test and the single value and pair value Grubbs tests (between laboratory means) [39]. The RSD $\mathrm{r}_{\mathrm{r}}$ and RSDR, and the HorRat value (the ratio of the RSDR to the predicted RSDR) were obtained using an analysis of variance according to AOAC guidelines [24]. The criteria for analytical methods mentioned in Commission Regulation (EC) No. $401 / 2006$ were used for evaluation of these parameters [33]. The Z-score compares the analytical result to the assigned value and can be used to describe the comparability of results. The Z-score was derived from the results of each participant according to the following equation [40]:

$$
\text { Z-score }=\frac{X_{\text {lab }}-X_{\text {ref }}}{\sigma_{\mathrm{p}}}
$$

where $X_{\text {lab }}$ is the result reported by the participant, expressed as a dimensionless mass ratio, e.g., $1 \mu \mathrm{g} / \mathrm{kg}=10^{-9} ; X_{\text {ref }}$ is the assigned value expressed as a dimensionless ratio, e.g., $1 \mu \mathrm{g} / \mathrm{kg}=10^{-9}$; and $\sigma_{\mathrm{P}}$ is the target standard deviation (SD) for proficiency assessment. The target $\mathrm{SD}\left(\sigma_{\mathrm{p}}\right)$ was calculated from the modified Horwitz equation:

$$
\sigma_{p}=\frac{0.22 \times c}{m r}
$$

where $\mathrm{c}$ is the concentration of the assigned value, expressed as a dimensionless mass ratio, e.g., $1 \mu \mathrm{g} / \mathrm{kg}=10^{-9}$; and mris the dimensionless mass ratio, $1 \mu \mathrm{g} / \mathrm{kg}=10^{-9}$. The Z-score classification was as follows: $|Z| \leq 2$, acceptable; $2<|Z| \leq 3$, questionable; $|Z|>3$, unacceptable.

Supplementary Materials: The following are available online at www.mdpi.com/2072-6651/8/12/371/s1, Figure S1: Chromatograms of multimycotoxins: (A) aflatoxin B1; (B) aflatoxin B2; (C) aflatoxin G1; (D) aflatoxin G2; and (E) STC.

Acknowledgments: This study was financially supported by the Ministry of Food and Drug Safety (15161MFDS012). We are grateful for the collaboration of the following participants in the interlaboratory study: Nongshim Co. Ltd. (Cheong-Tae Kim), Pulmuone Co. Ltd. (Sang Woo Cho), Korea Textile Inspection \& Testing Institute (Jang-Hyuk Ahn), Chung-Ang University (Chan Lee), Kyungpook National University (Sung-Eun Lee), and Wonkwang University (Hoon Choi).

Author Contributions: Designed experiments and interpreted data: H.S.C. Performed experiments: H.E.O., F.T. Statistical analysis: E.Y.H., S.H.K. Prepared and distributed samples: O.P., D.K. Wrote the manuscript: H.S.C., F.T.

Conflicts of Interest: The authors declare no conflict of interest.

\section{References}

1. Andrade, P.; de Mello, M.H.; França, J.; Caldas, E. Aflatoxins in food products consumed in Brazil: A preliminary dietary risk assessment. Food Addit. Contam. Part A 2013, 30, 127-136. [CrossRef] [PubMed]

2. Sugita-Konishi, Y.; Sato, T.; Saito, S.; Nakajima, M.; Tabata, S.; Tanaka, T.; Norizuki, H.; Itoh, Y.; Kai, S.; Sugiyama, K. Exposure to aflatoxins in Japan: Risk assessment for aflatoxin B1. Food Addit. Contam. 2010, 27, 365-372. [CrossRef] [PubMed]

3. Montes, R.; Segarra, R.; Castillo, M.-Á. Trichothecenes in breakfast cereals from the Spanish retail market. J. Food Compos. Anal. 2012, 27, 38-44. [CrossRef]

4. Trucksess, M.; Abbas, H.; Weaver, C.; Shier, W. Distribution of aflatoxins in shelling and milling fractions of naturally contaminated rice. Food Addit. Contam. Part A 2011, 28, 1076-1082. [CrossRef] [PubMed]

5. Rahmani, A.; Soleimany, F.; Hosseini, H.; Nateghi, L. Survey on the occurrence of aflatoxins in rice from different provinces of Iran. Food Addit. Contam. Part B 2011, 4, 185-190. [CrossRef] [PubMed]

6. Njumbe Ediage, E.; Van Poucke, C.; De Saeger, S. A multi-analyte LC-MS/MS method for the analysis of 23 mycotoxins in different sorghum varieties: The forgotten sample matrix. Food Chem. 2015, 177, 397-404. [CrossRef] [PubMed]

7. Hussaini, A.M.; Timothy, A.G.; Olufunmilayo, H.A.; Ezekiel, A.S.; Godwin, H.O. Fungi and some mycotoxins found in mouldy sorghum in Niger state, Nigeria. World J. Agric. Sci. 2009, 5, 5-17. 
8. Audilakshmi, S.; Stenhouse, J.; Reddy, T.; Prasad, M. Grain mould resistance and associated characters of sorghum genotypes. Euphytica 1999, 107, 91-103. [CrossRef]

9. Chandrashekar, A.; Bandyopadhyay, R.; Hall, A.J.; Chandrashekar, A.; Bandyopadhyay, R. Technical and institutional options for sorghum grain mold management. In Proceedings of the International Consultation, ICRISAT, Patancheru, India, 18-19 May 2000.

10. Sweeney, M.J.; Dobson, A.D. Mycotoxin production by aspergillus, fusarium and penicillium species. Int. J. Food Microbiol. 1998, 43, 141-158. [CrossRef]

11. Marin, S.; Ramos, A.; Cano-Sancho, G.; Sanchis, V. Mycotoxins: Occurrence, toxicology, and exposure assessment. Food Chem. Toxicol. 2013, 60, 218-237. [CrossRef] [PubMed]

12. International Agency for Research on Cancer (IARC). Agents Classified by the IARC Monographs, Volumes 1-116. Available online: https://monographs.iarc.fr/ENG/Classification/ClassificationsAlpha Order.pdf (accessed on 16 July 2016).

13. Bennett, J.; Klich, M. Chotoxins. C lin. Microbiol. Rev 2003, 16, 497-516. [CrossRef]

14. European Commission. Commission regulation (EU) no 165/2010 of 26 February 2010 amending regulation (EC) no 1881/2006 setting maximum levels for certain contaminants in foodstuffs as regards aflatoxins (text with eea relevance). Off. J. Eur. Union 2010, 038, 244-248.

15. Korea Food and Drug Administration (KFDA). Food Code, KFDA Notification No 2011-42; Korea Food and Drug Administration: Seoul, Korea, 2011.

16. Veršilovskis, A.; De Saeger, S. Sterigmatocystin: Occurrence in foodstuffs and analytical methods-An overview. Mol. Nutr. Food Res. 2010, 54, 136-147. [CrossRef] [PubMed]

17. World Health Organization. International agency for research on cancer (IARC) working group on the evaluation of carcinogenic risks to humans. In Overall Evaluations of Carcinogenicity: An Updating of IARC Monographs Volumes 1 to 42; World Health Organization: Geneva, Switzerland, 1987; Volume 7.

18. Sengun, I.; Yaman, D.B.; Gonul, S. Mycotoxins and mould contamination in cheese: A review. World Mycotoxin J. 2008, 1, 291-298. [CrossRef]

19. Zastempowska, E.; Grajewski, J.; Twarużek, M. Food-borne pathogens and contaminants in raw milk-A review. Ann. Anim. Sci. 2016. [CrossRef]

20. Veršilovskis, A.; Bartkevičs, V.; Mikselsone, V. Sterigmatocystin presence in typical Latvian grains. Food Chem. 2008, 109, 243-248. [CrossRef] [PubMed]

21. Mo, H.G.J.; Pietri, A.; MacDonald, S.J.; Anagnostopoulos, C.; Spanjere, M. Survey on sterigmatocystin in food. EFSA Support. Publ. 2015, 12. [CrossRef]

22. Oueslati, S.; Blesa, J.; Moltó, J.C.; Ghorbel, A.; Mañes, J. Presence of mycotoxins in sorghum and intake estimation in Tunisia. Food Addit. Contam. Part A 2014, 31, 307-318. [CrossRef] [PubMed]

23. Chala, A.; Taye, W.; Ayalew, A.; Krska, R.; Sulyok, M.; Logrieco, A. Multimycotoxin analysis of sorghum (Sorghum bicolor L. Moench) and finger millet (Eleusine coracana L. Garten) from Ethiopia. Food Control 2014, 45, 29-35. [CrossRef]

24. Association of Official Analytical Chemists (AOAC) International. Official Methods of Analysis of AOAC International; AOAC International: Gaithersburg, MD, USA, 2005.

25. Veršilovskis, A.; De Saeger, S.; Mikelsone, V. Determination of sterigmatocystin in beer by high performance liquid chromatography with ultraviolet detection. World Mycotoxin J. 2008, 1, 161-166. [CrossRef]

26. Ok, H.E.; Chung, S.H.; Lee, N.; Chun, H.S. Simple high-performance liquid chromatography method for the simultaneous analysis of aflatoxins, ochratoxin $\mathrm{A}$, and zearalenone in dried and ground red pepper. J. Food Prot. 2015, 78, 1226-1231. [CrossRef] [PubMed]

27. Tanaka, K.; Sago, Y.; Zheng, Y.; Nakagawa, H.; Kushiro, M. Mycotoxins in rice. Int. J. Food Microbiol. 2007, 119, 59-66. [CrossRef] [PubMed]

28. Veršilovskis, A.; Van Peteghem, C.; De Saeger, S. Determination of sterigmatocystin in cheese by high-performance liquid chromatography-tandem mass spectrometry. Food Addit. Contam. 2009, 26, 127-133. [CrossRef] [PubMed]

29. Sulyok, M.; Berthiller, F.; Krska, R.; Schuhmacher, R. Development and validation of a liquid chromatography/tandem mass spectrometric method for the determination of 39 mycotoxins in wheat and maize. Rapid Commun. Mass Spectrom. 2006, 20, 2649-2659. [CrossRef] [PubMed] 
30. Sulyok, M.; Krska, R.; Schuhmacher, R. A liquid chromatography/tandem mass spectrometric multi-mycotoxin method for the quantification of 87 analytes and its application to semi-quantitative screening of moldy food samples. Anal. Bioanal. Chem. 2007, 389, 1505-1523. [CrossRef] [PubMed]

31. Frenich, A.G.; Vidal, J.L.M.; Romero-González, R.; del Mar Aguilera-Luiz, M. Simple and high-throughput method for the multimycotoxin analysis in cereals and related foods by ultra-high performance liquid chromatography/tandem mass spectrometry. Food Chem. 2009, 117, 705-712. [CrossRef]

32. Böhm, J.; De Saeger, S.; Edler, L.; Fink-Gremmels, J.; Mantle, P.; Peraica, M.; Stetina, R.; Vrabcheva, T. Scientific opinion on the risk for public and animal health related to the presence of sterigmatocystin in food and feed. Eur. Food Saf. Auth. J. 2013, 11, 1-81.

33. European Commission. No 401/2006 of 23 February 2006. Laying down the methods of sampling and analysis for the official control of the levels of mycotoxins in foodstuffs. Off. J. Eur. Union L 2006, 70, 12-34.

34. Horwitz, W.; Albert, R. The horwitz ratio (horrat): A useful index of method performance with respect to precision. J. AOAC Int. 2006, 89, 1095-1109. [PubMed]

35. Veršilovskis, A.; Bartkevičs, V.; Miķelsone, V. Analytical method for the determination of sterigmatocystin in grains using high-performance liquid chromatography-tandem mass spectrometry with electrospray positive ionization. J. Chromatogr. A 2007, 1157, 467-471. [CrossRef] [PubMed]

36. Sasaki, R.; Hossain, M.; Abe, N.; Uchigashima, M.; Goto, T. Development of an analytical method for the determination of sterigmatocystin in grains using LCMS after immunoaffinity column purification. Mycotoxin Res. 2014, 30, 123-129. [CrossRef] [PubMed]

37. Association of official analytical chemists (AOAC). Natural Toxins: Aflatoxins. In Official Methods of Analysis, 18th ed.; International Association of Official Analytical Chemists: Gaithersburg, MD, USA, 2005; Volume Chapter 49; p. 4.

38. Miller, J.C.; Miller, J.N. Statistics for Analytical Chemistry; John Wiley and Sons: New York, NY, USA, 1988.

39. Horwitz, W. Protocol for the design, conduct and interpretation of method-performance studies: Revised 1994 (technical report). Pure Appl. Chem. 1995, 67, 331-343. [CrossRef]

40. Thompson, M.; Ellison, S.L.; Wood, R. The international harmonized protocol for the proficiency testing of analytical chemistry laboratories (IUPAC technical report). Pure Appl. Chem. 2006, 78, 145-196. [CrossRef]

(C) 2016 by the authors; licensee MDPI, Basel, Switzerland. This article is an open access article distributed under the terms and conditions of the Creative Commons Attribution (CC-BY) license (http://creativecommons.org/licenses/by/4.0/). 